\title{
THE UNROLLING OF THE LEAVES OF SUGAR CANE
}

Melville T. Cook, Chief of the Division of Plant Pathology

The unrolling of the leaves of monocotyledonous plants, such as sugar cane and corn is such a common phenomenon that it appears to have been overlooked by students and writers. While pursuing studies on the mosaic disease of the sugar cane the attention of the writer was attracted to the anatomical structures involved in the unrolling of the leaf. Before discussing this point it will be necessary to call attention to the structure of the mature leaf. In the mature leaf we find three sizes of fibro-vascular bundles. The largest constitute the parallel veins which are so well defined in the leaf as to be visible to the naked eye and extend from epidermis to epidermis. The other two sizes are arranged alternately and the number between any two of the veins is variable, but fairly constant for each variety. The medium-sized bundles are always in contact with the outer or lower epidermis and may or may not be in contact with the upper or inner epidermis. The space between the upper and lower epidermis which is not taken up by the fibro-vascular is filled with parenchyma cells of many sizes, the smaller ones being next to the bundles and to the lower epidermis which are in contact with the larger bundles coming in contact with the upper epidermis. The medium-sized cells are between the bundles. The largest cells are in contact with or very near the upper epidermis. In some cases they supplant the ordinary type of epidermis and in fact are large epidermis cells which extend far into the tissues of the leaf and have a thin cuticle on the exposed surface. Therefore, there is much more parenchyma near the upper than near the lower epidermis and the large cells are nearer the upper epidermis.

It is these large parenchyma or giant cells that are most important in the unrolling of the leaves. When the leaf is young the fibro vaseular bundles are poorly developed and there is a much greater uniformity in the size of the parenchyma cells than in the mature leaf. The fibro-vascular bundles mature with the increase in age and certain of the parenchyma cells near the inner or upper epidermis increase in size very rapidly and become the giant cells. The lateral enlargement of these giant cells force the leaves to unroll and assume the normal position.

These large cells are probably filled with water and with the 
unrolling of the leaf they are exposed to the direct rays of the sun which naturally aids evaporation. The loss of water from these cells naturally results in a contraction and upward rolling of the cells which is so characteristic of plants of this kind during periods of drouth.

\section{EXPLANATION OF PLATES}

Fig. 1.-Cross section through a very young leaf before it has started to unroll. u. $e .=$ upper epidermis. l.e.=lower epidermis. Note the very young fibro-vascular bundles; the uniform character of the mesophyll cells, some few of which are enlarging.

Fig. 2.-Cross section of an older leaf just starting to unroll. Note the increased development of the fibro-vascular bundles and the great variation in size of parenchyma cells as compared with Fig. 1.

Fig. 3.-Cross section of a leaf fully unrolled. Note the fibrovascular bundle's which are almost fully developed and the great variation in size of the parenchyma cells. Note the very large parenchyma cells near the upper epidermis. It is the lateral enlargement of these cells which force's the unrolling of the leaf. 
PLATE I

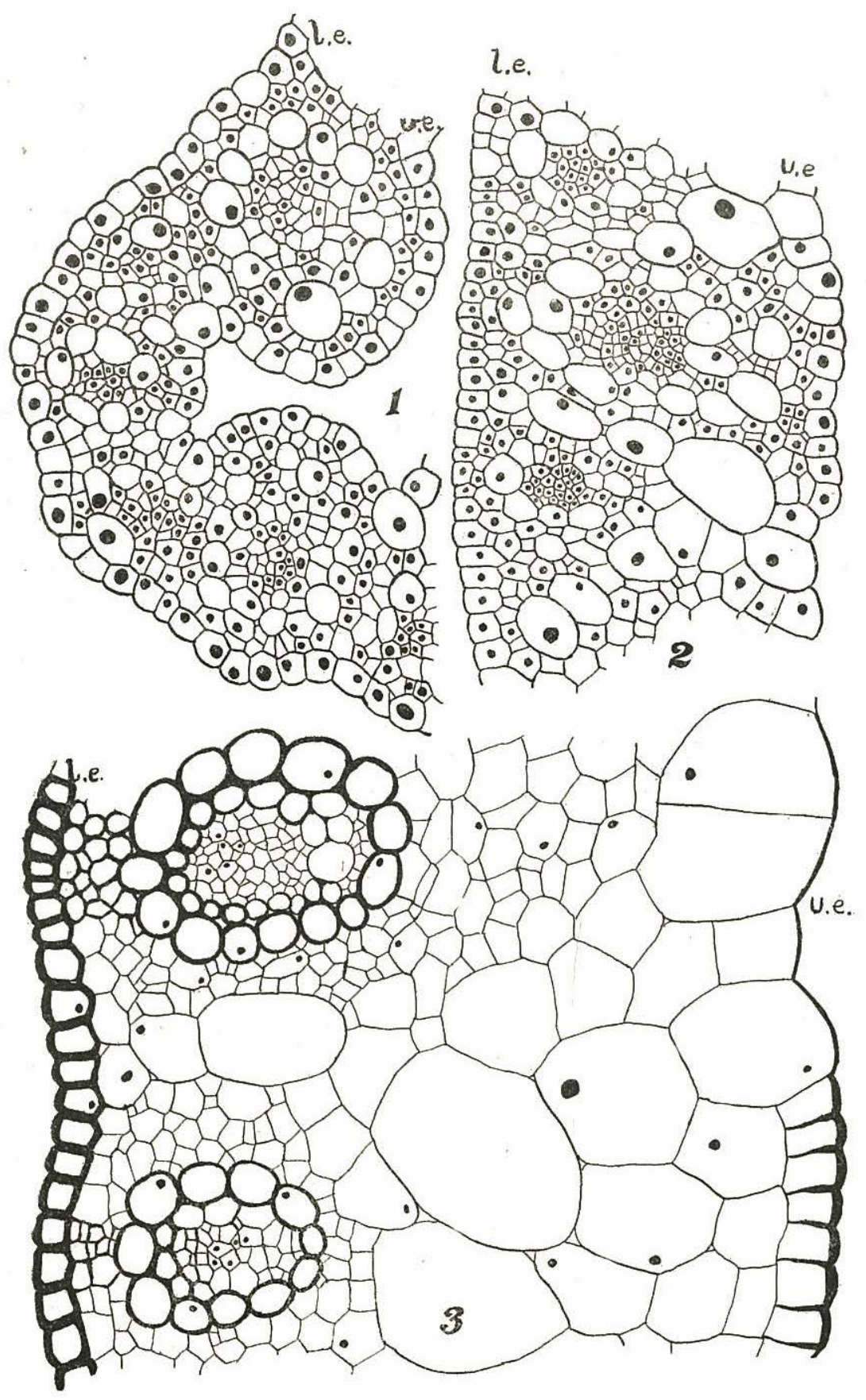

